\title{
Social Support and Attachment to Pets Moderate the Association between Sexual and Gender Minority Status and the Likelihood of Delaying or Avoiding COVID-19 Testing
}

\author{
Angela Matijczak ${ }^{1, *(\mathbb{D})}$, Jennifer W. Applebaum ${ }^{2} \mathbb{(}$, Shanna K. Kattari ${ }^{3}(\mathbb{C})$ and Shelby E. McDonald ${ }^{4}(\mathbb{C}$ \\ 1 School of Social Work, Virginia Commonwealth University, 1000 Floyd Ave, Richmond, VA 23284, USA \\ 2 Department of Sociology and Criminology \& Law, University of Florida, 3219 Turlington Hall, \\ Gainesville, FL 32611, USA; jennyapplebaum@ufl.edu \\ 3 School of Social Work and College of Literature, Science, and the Arts Department of Women's and Gender \\ Studies, University of Michigan, Ann Arbor, MI 48109, USA; skattari@umich.edu \\ 4 Children, Families, and Animals Research (CFAR) Group, LLC, Richmond, VA 23223, USA; \\ cfargroup@gmail.com \\ * Correspondence: matijczaka@vcu.edu
}

\section{check for} updates

Citation: Matijczak, Angela, Jennifer W. Applebaum, Shanna K. Kattari, and Shelby E. McDonald. 2021. Social Support and Attachment to Pets Moderate the Association between Sexual and Gender Minority Status and the Likelihood of Delaying or Avoiding COVID-19 Testing. Social Sciences 10: 301. https://doi.org/ 10.3390/socsci10080301

Academic Editor: Lauren Dundes

Received: 29 June 2021

Accepted: 8 August 2021

Published: 10 August 2021

Publisher's Note: MDPI stays neutra with regard to jurisdictional claims in published maps and institutional affiliations.

Copyright: (c) 2021 by the authors. Licensee MDPI, Basel, Switzerland. This article is an open access article distributed under the terms and conditions of the Creative Commons Attribution (CC BY) license (https:// creativecommons.org/licenses/by/ $4.0 /)$.
Abstract: Sexual and gender minority individuals (SGM) face barriers to accessing COVID-19 testing and treatment services. Living with pets may pose an additional barrier due to concerns about pet welfare. This study investigates whether the relation between SGM status and the likelihood of delaying or avoiding testing and treatment for COVID-19 varies as a function of attachment to pets and social support. Our sample consisted of 1453 adults $\left(M_{\text {age }}=39.4\right.$ years, $12.6 \%$ racial/ethnic minority; $21.8 \%$ SGM). We conducted simple and additive multiple moderation analyses to investigate the moderating effect of attachment to pets and social support on the relation between SGM status and the likelihood of delaying or avoiding COVID-19 testing or treatment. Attachment to pets moderated the association between SGM status and the likelihood of delaying or avoiding COVID-19 testing in the simple $(\beta=0.82, Z=2.09, p=0.04)$ and additive multiple moderation analyses $(\beta=0.82, Z=2.05$, $p=0.04)$. SGM participants were more likely than non-SGM participants to report that they would delay or avoid testing when they reported high attachment to their pet $(\beta=0.75, O R=2.11, Z=2.51$, $p=0.01)$ and low $(\beta=0.75, O R=2.12, Z=2.48, p=0.01)$ or moderate $(\beta=0.73, O R=2.08, Z=2.14$, $p=0.03)$ levels of social support.

Keywords: COVID-19; sexual and gender minority; LGBTQ; pets; companion animals; social support

\section{Introduction}

As of June 2021, the Centers for Disease Control (CDC) estimates that there have been more than 33,000,000 cases of COVID-19 in the U.S., contributing to more than 590,000 deaths (Centers for Disease Control and Prevention 2021a). Several studies have documented the psychological toll of the pandemic with reports of increased anxiety and depressive symptoms, substance abuse, and suicidal ideation among adults (Czeisler et al. 2020; Ettman et al. 2020; Holman et al. 2020; McGinty et al. 2020; Shanahan et al. 2020). Further, many individuals are faced with additional economic stressors, such as unemployment, eviction, and food insecurity (Benfer et al. 2021; Couch et al. 2020; Leddy et al. 2020).

\subsection{COVID-19 in the Sexual and Gender Minority Population}

There is emerging evidence that marginalized groups, such as sexual and gender minority (SGM) individuals, have been disproportionately impacted by the COVID-19 pandemic in the U.S. (Ahmed et al. 2020; Fish et al. 2021; Kamal et al. 2021; Kantamneni 2020; Veldhuis et al. 2021). SGM people are those who identify with a sexual orientation other than heterosexual (e.g., bisexual, asexual, gay, lesbian, queer) and/or who identify with a gender that is not cisgender (e.g., transgender, genderqueer, nonbinary). Compared 
to their cisgender and heterosexual counterparts, SGM individuals may be at a heightened risk of contracting COVID-19 and experiencing more negative outcomes related to COVID19 for a variety of reasons (Gibb et al. 2020). For example, SGM individuals are more likely to have health conditions that elevate the risk associated with COVID-19, such as diabetes, cancer, and HIV / AIDS (Beach et al. 2018; Caceres et al. 2017, 2020; Gonzales and Henning-Smith 2017). Further, SGM people are more likely to experience poverty (Carpenter et al. 2020; Lee Badgett et al. 2019; Schneebaum and Badgett 2019) and housing instability (Romero et al. 2020), work in jobs that put them at a higher risk of contracting COVID-19 (e.g., restaurants, retail; (Whittington et al. 2020), and are less likely to have health insurance (Whittington et al. 2020).

Access to COVID-19 testing and treatment have played an important role in understanding and preventing the spread of COVID-19 across the U.S. (Binnicker 2020; Shadmi et al. 2020). In general, there is evidence that SGM individuals experience high rates of discrimination from health care providers $(8 \%$ of sexual minorities and $29 \%$ of transgender individuals; Mirza and Rooney 2018). It is therefore not surprising that approximately one in four transgender individuals, or more broadly $8 \%$ of SGM individuals, report that they avoid doctor's offices and accessing other healthcare services due to fear of discrimination or being misgendered (James et al. 2016; Mirza and Rooney 2018). There is emerging evidence that rates of COVID-19 testing among SGM populations are low, compared to testing rates among the overall U.S. population (Martino et al. 2021; Phillips et al. 2021). However, the research on how SGM status relates to decisions to seek COVID-19 related services is limited, due to the lack of information on sexual orientation and/or gender identity on CDC reports (Krause 2021; Sell and Krims 2021). It is vital to identify factors that account for differences in healthcare decision-making between SGM individuals and those who identify as heterosexual and cisgender.

\subsection{Companion Animals and the COVID-19 Pandemic}

The role of companion animals, or pets, in promoting health and wellbeing is one area that has received increased research and media attention during the COVID-19 pandemic, particularly in relation to promoting health and wellbeing during social isolation (e.g., Applebaum et al. 2020b; May 2021; McDonald et al. 2021b; Ratschen et al. 2020, 2021). There is some evidence that pet owners reported less feelings of loneliness during the pandemic than those who did not own a pet (Ratschen et al. 2020). Additionally, living with a pet during the pandemic has been linked to greater engagement in physical activity (e.g., walking), better mood, and enhanced quality of life (Bowen et al. 2020; Shoesmith et al. 2021). Although there have not been any studies that have directly investigated the role of pets during the COVID-19 pandemic among SGM-only samples, evidence from studies conducted prior to the pandemic suggests that SGM people have strong bonds with their pets that provide social support, emotional comfort, and unconditional love (Dakin et al. 2020; MacNamara 2019; McDonald et al. 2021a; Putney 2014).

However, some studies also suggest that pets may have a negative influence on healthcare decisions. For examples, pet owners may delay medical care due to their pet (Peacock et al. 2012) or may refrain from entering IPV or homeless shelters to avoid being separated from their pet (Ascione et al. 2007; Cleary et al. 2020; Rhoades et al. 2015; Stevenson et al. 2018). Further, recent evidence suggests that there may be unique stressors associated with caring for a pet during the pandemic. For example, a qualitative study conducted by Applebaum et al. $2020 \mathrm{~b}$ found that pet owners reported a variety of petrelated stressors, such as concerns about being able to financially support their pet, worries about their pet's health and wellbeing, and difficulty managing emerging behavioral issues related to the disruption in normal schedules. One notable concern reported by pet owners across studies relates to the lack of social support to provide alternative care for pets in the event of pet owner illness or hospitalization due to COVID-19 (Adams et al. 2021; Applebaum et al. 2020a, 2020b). This may be a particular concern for SGM individuals, as there is evidence that SGM people report lower levels of social support than non-SGM 
individuals and, thus, may have less access to a social network to care for their pet in case of illness (Frost et al. 2016; Moore et al. 2021). Indeed, in a qualitative study conducted prior to the pandemic, SGM emerging adults living with pets noted experiencing caregiver burden and worrying about finding alternative caregivers for their pets, if needed (McDonald et al. 2021a). This suggests that attachment to pets and social support are important factors to consider when investigating differences in healthcare decision-making between SGM pet owners and non-SGM pet owners.

\subsection{Current Study}

This study builds on the results of the study conducted by Applebaum et al. (2020a) by examining how intentions to seek COVID-19 healthcare services differ between SGM pet owners compared to cisgender and heterosexual pet owners. The purpose of the current study is twofold: (a) to examine whether identifying with an SGM identity is related to the likelihood of delaying or avoiding COVID-19 testing and treatment, and (b) to identify whether and to what extent, the relations between SGM status and the likelihood of delaying or avoiding COVID-19 testing and treatment vary as a function of attachment to pets (Figure 1a,b). Additionally, we also examined a model that included attachment to pets and social support as moderators of the relation between SGM status and the likelihood of delaying or avoiding testing and treatment, when the other moderator is held constant (Figure 1c,d. We hypothesized that, compared to heterosexual and cisgender individuals, SGM individuals would be more likely to delay or avoid testing and treatment for COVID19 when they are highly attached to their pet(s). Additionally, we expected that the relation between SGM status and the likelihood of delaying or avoiding COVID-19 testing and treatment would be strongest for SGM participants who report greater attachment to pets and low levels of social support.

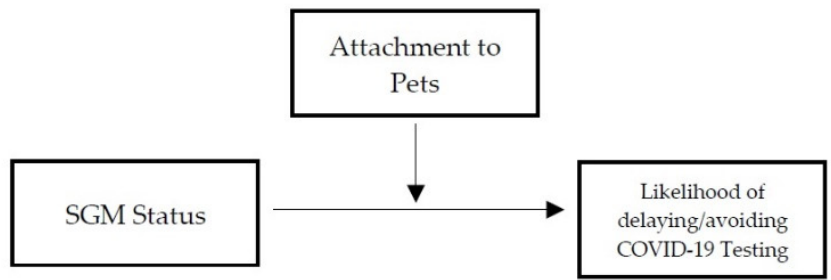

(a)

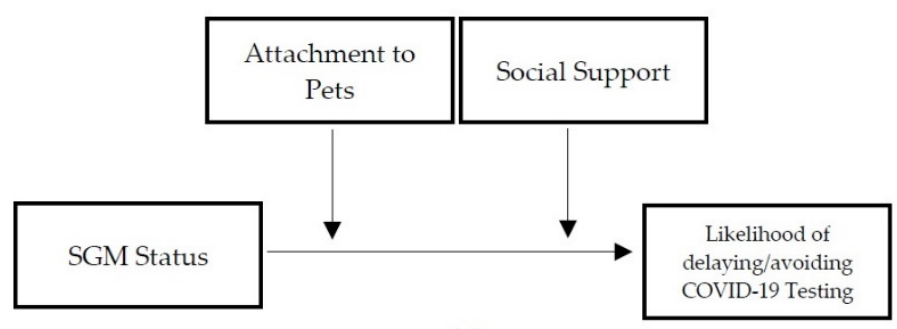

(c)

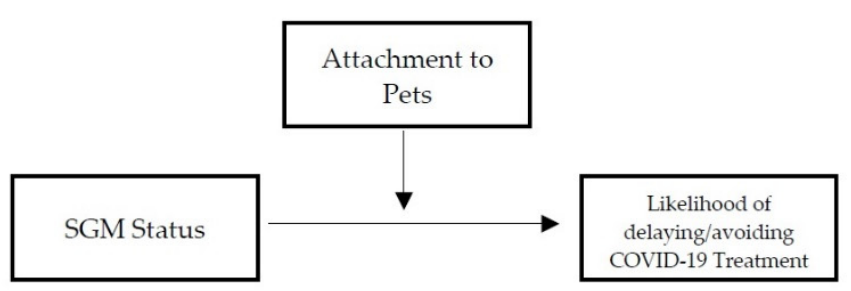

(b)

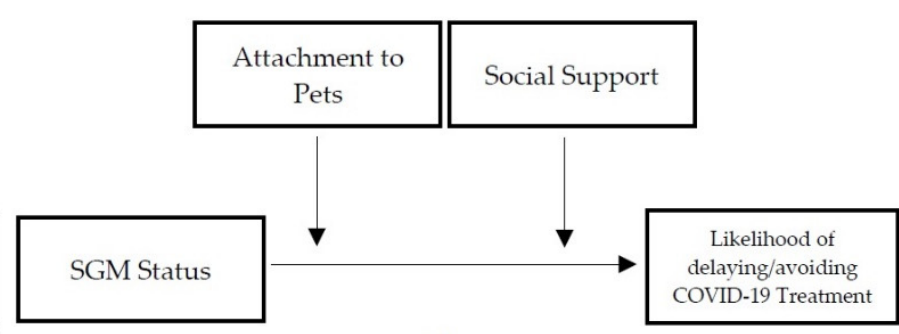

(d)

Figure 1. Conceptual models for the moderation analyses. Covariates are not shown in the figures for clarity. (a) Simple moderation model with the likelihood of delaying or avoiding COVID-19 testing as the outcome. (b) Simple moderation model with the likelihood of delaying or avoiding COVID-19 treatment as the outcome. (c) Additive multiple moderation model with the likelihood of delaying or avoiding COVID-19 testing as the outcome. (d) Additive multiple moderation model with the likelihood of delaying or avoiding COVID-19 treatment as the outcome.

\section{Materials and Methods}

The data analyzed in this study were collected through an anonymous Qualtrics survey shared online between April 2020 and July 2020. The survey was shared via social media (e.g., Facebook, Twitter, Instagram) and posted on online interest groups and 
listservs relating to animals. Participants were eligible to complete the survey if they were over the age of 18 years, currently resided in the U.S., could read written English, and endorsed that they lived with at least one pet or companion animal (defined as an "animal that lives with you, that you or a member of your household are primarily responsible for"). All participants completed informed consent prior to beginning the survey. Participants took an average of 30 minutes to complete the survey and were not compensated for their participation. All survey questions were optional and could be skipped, excluding the screening questions and informed consent. All procedures were approved by the University of Florida Internal Review Board (protocol \#IRB202000819).

\subsection{Participants}

A total of 3006 participants responded to the survey. After removing incomplete observations due to attrition $(n=929)$, missingness for all variables included in the analyses was less than $10 \%$, with the exception of the Lexington Attachment to Pets Scale (LAPS; Johnson et al. 1992), of which $18.1 \%$ of the sample was missing a response to at least one item. To further assess patterns of missingness, we conducted Little's Test of Missing Completely at Random (Little 1988), and found that the data were missing completely at random $\left(\chi^{2}(2)=3.51, p=0.17\right)$. Therefore, we removed all participants with missing data on variables included in the analyses; this yielded a final sample of 1453 participants. Approximately $22 \%$ of the total sample endorsed an SGM identity. Due to the small proportion of participants that identified as transgender and/or gender expansive $(3 \%$, $n=44$ ), we were limited to combining sexual and gender minority identities into one SGM status variable in the analysis plan. Table 1 reflects the demographic characteristics of the total sample, as well as characteristics split by SGM status. Dogs were the most frequently owned pet, with approximately $74.6 \%$ of the total sample indicating that they owned at least one dog. A little more than half (52.9\%) of the sample owned a cat, followed by $8.3 \%$ that owned a fish, $6.9 \%$ that owned a reptile (e.g., snake, turtle, lizard), $4.8 \%$ that owned a bird, $4.7 \%$ that owned a small mammal (e.g., rat, guinea pig, rabbit), 3.3\% that owned a horse, and $2.9 \%$ that reported on a different species of pet (e.g., cow, pig, donkey, chicken, axolotls).

Table 1. Demographic characteristics of sample $(n=1453)$.

\begin{tabular}{|c|c|c|c|c|c|c|c|}
\hline \multirow{2}{*}{ Variable } & \multirow[t]{2}{*}{ Variable Categories } & \multicolumn{2}{|c|}{$\begin{array}{c}\text { SGM } \\
(n=317)\end{array}$} & \multicolumn{2}{|c|}{$\begin{array}{l}\text { Cisgender and Heterosexual } \\
\qquad(n=1136)\end{array}$} & \multicolumn{2}{|c|}{$\begin{array}{l}\text { Total Sample } \\
\quad(n=1453)\end{array}$} \\
\hline & & $n$ & $\%$ & $n$ & $\%$ & $n$ & $\%$ \\
\hline \multirow{9}{*}{ Race/Ethnicity } & Arab/Arab American & 0 & 0 & 1 & 0.1 & 1 & 0.1 \\
\hline & Asian/Asian American & 6 & 1.9 & 26 & 2.3 & 32 & 2.2 \\
\hline & Black/African American & 3 & 0.9 & 6 & 0.5 & 9 & 0.6 \\
\hline & First Nations/Indigenous & 0 & 0 & 3 & 0.3 & 3 & 0.2 \\
\hline & Latino/Latina/Latinx & 10 & 3.2 & 27 & 2.4 & 37 & 2.5 \\
\hline & South Asian/Pacific Islander & 1 & 0.3 & 3 & 0.3 & 4 & 0.3 \\
\hline & White & 270 & 85.2 & 1000 & 88.0 & 1270 & 87.4 \\
\hline & Multiracial/Mixed Race & 25 & 7.9 & 61 & 5.4 & 86 & 5.9 \\
\hline & Prefer to self-describe & 2 & 0.6 & 9 & 0.8 & 11 & 0.8 \\
\hline \multirow{7}{*}{$\begin{array}{l}\text { Gender } \\
\text { Identity }\end{array}$} & Cisgender woman & 255 & 80.4 & 1048 & 92.3 & 1303 & 89.7 \\
\hline & Cisgender man & 14 & 4.7 & 86 & 7.6 & 101 & 7.0 \\
\hline & Genderqueer/gender non-conforming & 16 & 5.0 & 0 & 0 & 16 & 1.1 \\
\hline & Transgender man & 3 & 0.9 & 0 & 0 & 3 & 0.2 \\
\hline & Prefer to self-describe & 1 & 0.3 & 0 & 0 & 1 & 0.1 \\
\hline & Multiple identities & 24 & 7.6 & 0 & 0 & 24 & 1.7 \\
\hline & Prefer not to say & 3 & 0.9 & 0 & 0 & 3 & 0.2 \\
\hline
\end{tabular}


Table 1. Cont.

\begin{tabular}{|c|c|c|c|c|c|c|c|}
\hline \multirow{2}{*}{ Variable } & \multirow{2}{*}{ Variable Categories } & \multicolumn{2}{|c|}{$\begin{array}{c}\text { SGM } \\
(n=317)\end{array}$} & \multicolumn{2}{|c|}{$\begin{array}{l}\text { Cisgender and Heterosexual } \\
\qquad(n=1136)\end{array}$} & \multicolumn{2}{|c|}{$\begin{array}{l}\text { Total Sample } \\
\quad(n=1453)\end{array}$} \\
\hline & & $n$ & $\%$ & $n$ & $\%$ & $n$ & $\%$ \\
\hline \multirow{11}{*}{$\begin{array}{c}\text { Sexual } \\
\text { Orientation }\end{array}$} & Asexual & 14 & 4.4 & 0 & 0 & 14 & 1.0 \\
\hline & Bisexual & 117 & 36.9 & 0 & 0 & 117 & 8.1 \\
\hline & Demisexual & 8 & 2.5 & 0 & 0 & 8 & 0.6 \\
\hline & Gay & 14 & 4.4 & 0 & 0 & 14 & 1.0 \\
\hline & Heterosexual/straight & 4 & 1.3 & 1136 & 100.0 & 1140 & 78.5 \\
\hline & Lesbian & 37 & 11.7 & 0 & 0 & 37 & 2.5 \\
\hline & Pansexual & 22 & 6.9 & 0 & 0 & 22 & 1.5 \\
\hline & Queer & 17 & 5.4 & 0 & 0 & 17 & 1.2 \\
\hline & Multiple identities & 67 & 21.1 & 0 & 0 & 67 & 4.6 \\
\hline & Not sure/questioning & 13 & 4.1 & 0 & 0 & 13 & 1.0 \\
\hline & Prefer to self-describe & 4 & 1.3 & 0 & 0 & 4 & 0.3 \\
\hline \multirow{9}{*}{$\begin{array}{l}\text { Highest level } \\
\text { of education }\end{array}$} & Some high school/GED & 6 & 1.8 & 7 & 0.7 & 13 & 0.9 \\
\hline & High school graduate & 12 & 3.8 & 26 & 2.3 & 38 & 2.6 \\
\hline & Some college, no degree & 45 & 14.2 & 110 & 9.7 & 155 & 10.7 \\
\hline & Vocational-Tech program & 6 & 1.9 & 22 & 1.9 & 28 & 1.9 \\
\hline & Associate's degree & 18 & 5.7 & 65 & 5.7 & 83 & 5.7 \\
\hline & Bachelor's degree & 102 & 32.2 & 389 & 34.2 & 491 & 33.8 \\
\hline & Master's degree & 68 & 21.5 & 350 & 30.8 & 418 & 28.8 \\
\hline & Professional/Academic doctorate & 47 & 14.8 & 158 & 13.9 & 205 & 14.1 \\
\hline & Other & 13 & 4.1 & 8 & 0.7 & 21 & 1.4 \\
\hline
\end{tabular}

\subsection{Measures}

\subsubsection{SGM Status}

Two questions on the demographic survey asked participants to indicate their sexual orientation and gender identity. Participants were able to choose from a variety of sexual orientations (e.g., bisexual, queer, pansexual, heterosexual) and gender identities (e.g., cisgender man/woman, transgender man/woman, genderqueer). These responses were then recoded so that participants who indicated that they were heterosexual and cisgender were coded as non-SGM (=0) and participants who selected a sexual orientation other than heterosexual and/or a gender identity other than cisgender were coded as an SGM (=1).

\subsubsection{Likelihood of Delaying or Avoiding COVID-19 Testing and Treatment}

Participants responded to two questions that measured their intent to delay or avoid testing and treatment for COVID-19 due to concerns about their pet's welfare. Specifically, the questions asked: "If you thought you had COVID-19, would you delay or avoid testing because you were worried about your pet's welfare?" and "If you thought you had COVID-19, would you delay or avoid treatment because you were worried about your pet's welfare?". Participants were able to select one of five options in response (i.e., yes, maybe, no, I don't know, prefer not to say); these responses were recoded so that "yes" or "maybe" = 1, "no" = 0, and "I don't know" or "prefer not to say" were coded as missing.

\subsubsection{Attachment to Pets}

Attachment to pets was measured using the LAPS (Johnson et al. 1992), a 23-item instrument that measures emotional attachment across four domains: love, emotion regulation, personal growth, and negative impact (reverse scored). The LAPS Likert response scale ranges from 1 (strongly disagree) to 4 (strongly agree). Participants were instructed to think about their favorite pet when answering the questions. Responses to all items (e.g., "My pet makes me feel happy", "I feel that my pet is a part of my family") were summed to yield a total score of overall pet attachment $(\omega=0.91)$. 


\subsubsection{Social Support}

The Multidimensional Scale of Perceived Social Support (MSPSS; Zimet et al. 1988) was used to measure levels of overall social support. The MSPSS consists of 12 items that assess perceived social support received from multiple sources (i.e., friends, family, significant other). Example items include "I can talk about my problems with my friends" and "I get the emotional help and support I need from my family". Participants responded to each item using a 7-point Likert scale ranging from 1 (strongly disagree) to 7 (strongly agree). All items were averaged to yield a total score $(\omega=0.93)$.

\subsubsection{Covariates}

Across all models, we adjusted for the effect of age (continuous); race/ethnicity (racial/ethnic minority $=0$, White, non-Latinx $=1$ ); whether the participant was in a relationship (not in a relationship $=0$, in a relationship $=1$ ), has a child (no children $=0$, at least one child $=1$ ), or has a roommate (no roommate $=0$, lives with roommate $=1$ ); education level (no college $=0$, some college education or higher $=1$ ); whether the participant was at risk of losing a job (no or not sure $=0$, yes or already laid off $=1$ ) or was worried about losing their income (no $=0$, yes or somewhat $=1)$; whether the participant had health insurance (no $=0$, yes $=1$ ); and social support (continuous; only in simple moderation models). A demographic questionnaire measured all covariates excluding social support, which was measured using the MSPSS.

\subsection{Analysis Plan}

All analyses for this study were conducted using SPSS Statistics (version 27); the moderation analyses were conducted using the PROCESS macro (version 3.5; Hayes 2017). We conducted two simple moderation analyses that tested whether, and to what extent, the relation between SGM status and the likelihood of delaying or avoiding COVID-19 testing and treatment varied as a function of attachment to pets (Figure 1a,b). Then, we conducted two additive multiple moderation models that included both attachment to pets and social support as moderators of the association between SGM status and the likelihood of delaying or avoiding COVID-19 testing and treatment (Figure 1c,d). The covariates discussed above were included in all models.

\section{Results}

Intercorrelations, frequencies, percentages, means, and standard deviations of all key variables can be found in Table 2 . The majority of participants $(63.7 \%)$ answered the LAPS based on their pet dog, followed by $32.4 \%$ who responded based on a pet cat; the remaining $3.7 \%$ of participants responded based on another species of pet (e.g., reptile, fish, horse). Attachment to pets and social support were significantly related, but the association did not violate the assumption of multicollinearity. Values for VIF and tolerance were within an acceptable range (Hair et al. 2010). Across both the simple and multiple moderation models, participants who were in a relationship were less likely to indicate that they would delay or avoid COVID-19 testing or treatment. Additionally, those who had a child were significantly less likely to indicate that they would delay or avoid COVID-19 treatment and those who were worried about their income were significantly more likely to indicate that they would delay or avoid COVID-19 treatment. There were no other significant associations between covariates and the dependent variables in the moderation models. See Table S1 for more detailed information on relations between the covariates and outcomes of interest. 
Table 2. Intercorrelations between key variables $(\mathrm{N}=1453)$.

\begin{tabular}{|c|c|c|c|c|c|c|c|c|c|c|c|c|c|c|}
\hline Variable Name & 1 & 2 & 3 & 4 & 5 & 6 & 7 & 8 & 9 & 10 & 11 & 12 & 13 & 14 \\
\hline 1. Relationship status ${ }^{a}$ & - & & & & & & & & & & & & & \\
\hline 2. Children ${ }^{b}$ & $0.21 * *$ & - & & & & & & & & & & & & \\
\hline 3. Education level ${ }^{\mathrm{c}}$ & $0.10 * *$ & $0.05 *$ & - & & & & & & & & & & & \\
\hline 4. Race/Ethnicity ${ }^{d}$ & 0.04 & 0.02 & 0.03 & - & & & & & & & & & & \\
\hline 5. Roommates $\mathrm{e}^{\mathrm{e}}$ & $-0.10^{* *}$ & $-0.09^{* *}$ & $-0.10^{* *}$ & $-0.05^{*}$ & - & & & & & & & & & \\
\hline 6. Employment risk $\mathrm{f}$ & $-0.07^{* *}$ & -0.01 & $-0.12 * *$ & -0.03 & $0.12 * *$ & - & & & & & & & & \\
\hline 7. Age & $0.08 * *$ & $0.07^{* *}$ & 0.02 & $0.09 * *$ & $-0.22 *$ & $-0.08^{* *}$ & - & & & & & & & \\
\hline 8. Income Worry $\mathrm{g}$ & $0.07 * *$ & 0.02 & -0.04 & $-0.07 * *$ & $0.06^{*}$ & $0.19^{* *}$ & -0.03 & - & & & & & & \\
\hline 9. Health insurance ${ }^{h}$ & $0.07 * *$ & $0.07^{* *}$ & $0.15^{* *}$ & 0.06 * & $-0.06^{*}$ & $-0.14^{* *}$ & $0.08^{* *}$ & -0.01 & - & & & & & \\
\hline 11. Social support & $0.26^{* *}$ & 0.06 * & $0.07^{* *}$ & 0.01 & 0.03 & $-0.09 * *$ & $-0.12^{* *}$ & -0.04 & $0.06^{*}$ & $-0.10^{* *}$ & - & & & \\
\hline 12. SGM Status ${ }^{\mathrm{i}}$ & $-0.10 * *$ & $-0.10 * *$ & $-0.10^{* *}$ & -0.04 & $0.09^{* *}$ & 0.06 * & $-0.21 * *$ & 0.01 & $-0.05 *$ & 0.02 & -0.03 & - & & \\
\hline 13. Likelihood of delaying/avoiding COVID-19 testing ${ }^{j}$ & $-0.12 * *$ & $-0.09 * *$ & 0.01 & 0.03 & 0.03 & $0.06^{*}$ & 0.01 & 0.03 & -0.03 & $0.10^{* *}$ & $-0.13^{* *}$ & 0.05 & - & \\
\hline $\begin{array}{l}\text { 14. Likelihood of delaying/avoiding COVID-19 } \\
\text { treatment }{ }^{k}\end{array}$ & $-0.11^{* *}$ & $-0.11^{* *}$ & -0.02 & 0.04 & 0.02 & 0.02 & 0.01 & 0.05 & -0.05 & $0.12 * *$ & $-0.15^{* *}$ & $0.06^{*}$ & $0.58^{* *}$ & - \\
\hline M/Frequency ${ }^{1}$ & 953 & 271 & 1211 & 1270 & 364 & 183 & 39.36 & 977 & 1405 & 80.83 & 4.08 & 317 & 96 & 134 \\
\hline$S D / \%^{1}$ & $65.6 \%$ & $18.7 \%$ & $83.3 \%$ & $87.4 \%$ & $25.1 \%$ & $12.6 \%$ & 13.20 & $67.2 \%$ & $96.7 \%$ & 8.72 & .83 & $21.8 \%$ & $6.6 \%$ & $9.2 \%$ \\
\hline
\end{tabular}

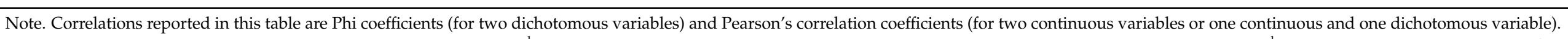

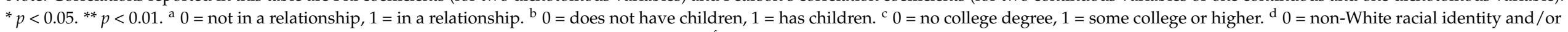

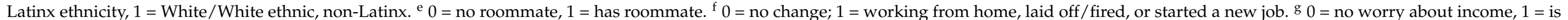

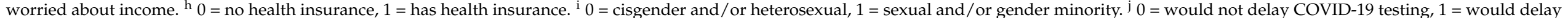

COVID-19 testing. ${ }^{k} 0=$ would not delay COVID-19 treatment, $1=$ would delay COVID-19 treatment. ${ }^{1}$ Frequencies and percentages reflect those with a value of 1. 


\subsection{Simple Moderation Analysis}

\subsubsection{Likelihood of Delaying or Avoiding COVID-19 Testing}

The model testing attachment to pets as a moderator of the relation between SGM status and the likelihood of delaying or avoiding testing for COVID-19 was a better fit to the data than the null model $(L L(13)=68.53, p<0.001)$ and the model explained a small amount of the variance in intent to avoid or delay COVID-19 testing (Cox and Snell $=0.05$, Nagelkerke $=0.12)$. Neither SGM status $(\beta=-0.02, Z=-0.07, p=0.94,95 \%$ $\mathrm{CI}=-0.69,0.64)$ nor attachment to pets $(\beta=0.29, Z=1.81, p=0.07,95 \% \mathrm{CI}=-0.02,0.60)$ were significant predictors of intent to delay or avoid testing for COVID-19. However, attachment to pets did significantly moderate the relation between SGM status and the likelihood of delaying or avoiding COVID-19 testing ( $\beta=0.82, Z=2.09, p=0.04,95 \%$ $\mathrm{CI}=0.05,1.60)$. An analysis of the conditional effects indicated that SGM participants were more likely to indicate that they would delay or avoid COVID-19 testing when they reported high levels of attachment to their pets $(\beta=0.75, O R=2.11, Z=2.51, p=01,95 \%$ $\mathrm{CI}=0.16,1.33$ ). There was no significant association between SGM status and the likelihood of delaying or avoiding COVID-19 testing when attachment to pets was at low $(\beta=-0.94$, $Z=-1.24, p=0.22,95 \% C I=-2.06,0.47)$ or moderate levels $(\beta=0.25, Z=0.63, p=0.53$, $95 \% \mathrm{CI}=-0.38,0.74)$. Figure $2 \mathrm{a}$ demonstrates the plots of the conditional effects.
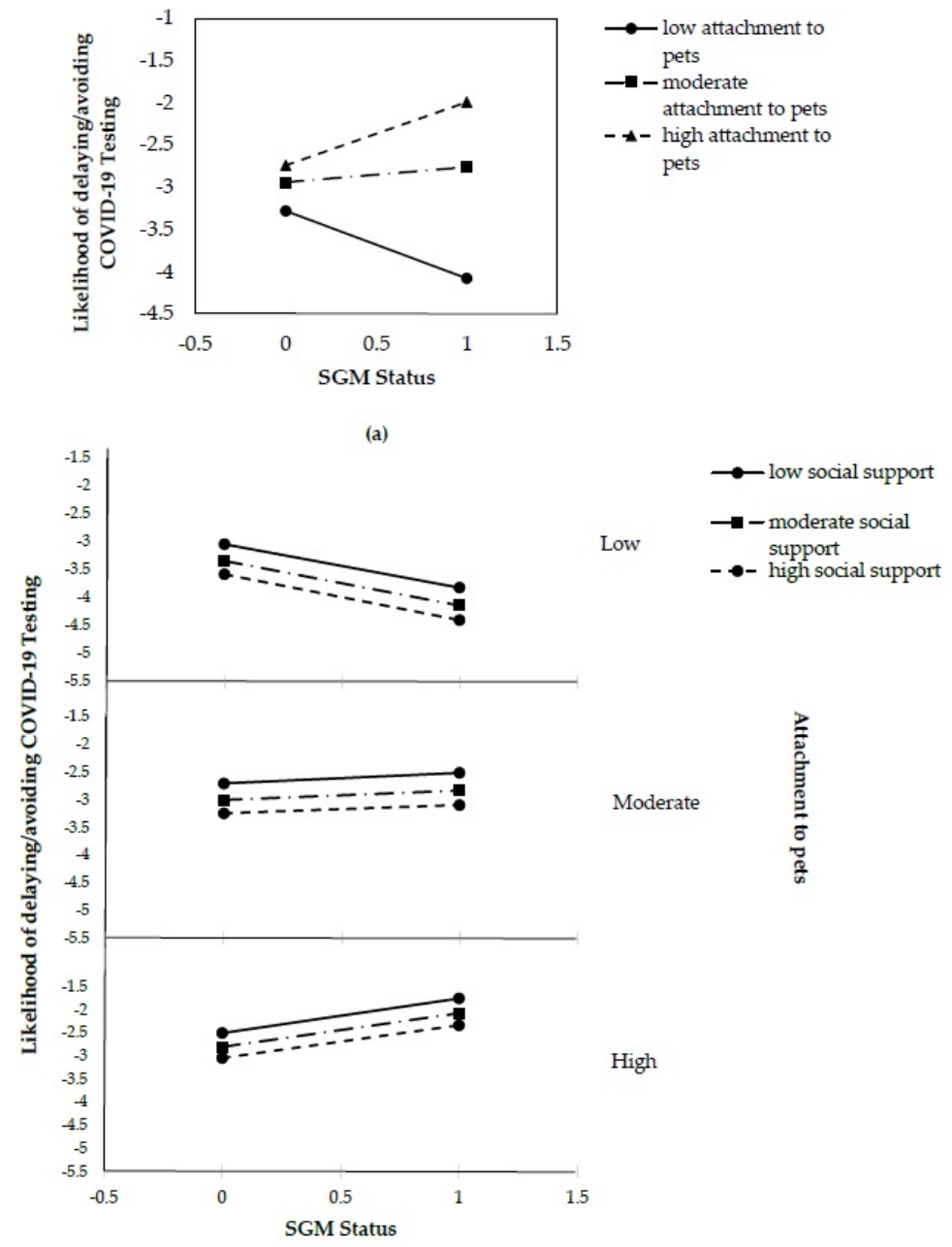

(b)

Figure 2. Significant conditional effects of simple and additive multiple moderation analyses $(N=1453)$. (a) Conditional effect of SGM status on the likelihood of delaying or avoiding COVID-19 testing as a function of attachment to pets. (b) Conditional effect of SGM status on the likelihood of delaying or avoiding COVID-19 treatment as a function of attachment to pets and social support. 


\subsubsection{Likelihood of Delaying or Avoiding COVID-19 Treatment}

The overall model with the likelihood of delaying or avoiding COVID-19 treatment was also a better fit to the data than the null model $(L L(13)=82.77, p<0.001)$. This model accounted for a small amount of the variance in intent to delay or avoid COVID-19 treatment $($ Cox and Snell $=0.06$, Nagelkerke $=0.12)$. SGM status was not related to the likelihood of delaying or avoiding treatment for COVID-19 ( $\beta=0.23, Z=0.87, p=0.38$, $95 \% \mathrm{CI}=-0.28,0.73$ ). However, attachment to pets was positively related to the likelihood of delaying or avoiding COVID-19 treatment $(\beta=0.32, Z=2.31, p=0.02,95 \% \mathrm{CI}=0.05$, $0.60)$. We did not find evidence that attachment to pets significantly moderated the relation between SGM status and intent to delay or avoid COVID-19 treatment $(\beta=0.48, Z=1.58$, $p=0.11,95 \% \mathrm{CI}=-0.12,1.07)$.

\subsection{Additive Multiple Moderation Analysis}

\subsubsection{Likelihood of Delaying or Avoiding COVID-19 Testing}

In the additive multiple moderation model with intent to avoid or delay COVID-19 testing as the outcome, the overall model was a better fit for the data than the null model $(L L(14)=68.54, p<0.001)$ and accounted for a small amount of the variance (Cox and Snell $=0.05$, Nagelkerke $=0.12$ ). There were no significant associations between intent to avoid or delay testing for COVID-19 and SGM status $(\beta=-0.03, Z=-0.09, p=0.93$, $95 \% \mathrm{CI}=-0.71,0.65)$ or attachment to pets $(\beta=0.29, Z=1.81, p=0.07,95 \% \mathrm{CI}=-0.02$, $0.60)$. Social support was significantly and negatively related to the likelihood of delaying or avoiding COVID-19 testing $(\beta=-0.30, Z=-2.79, p=0.01,95 \% \mathrm{CI}=-0.51,-0.09)$. However, social support did not significantly moderate the relation between SGM status and the likelihood of delaying or avoiding COVID-19 testing, when attachment to pets was held constant $(\beta=-0.02, Z=-0.10, p=0.92,95 \% C I=-0.46,0.41)$. We found evidence of a significant moderating effect of attachment to pets on this relation, when social support was held constant $(\beta=0.82, Z=2.05, p=0.04,95 \% C I=0.03,1.60)$. Results of the conditional effects indicate that SGM participants are more likely to endorse intent to delay or avoid testing for COVID-19 when they report high levels of attachment to their pet and low social support $(\beta=0.75, O R=2.12, Z=2.48, p=0.01,95 \% C I=0.16,1.35$ ) or moderate levels of social support $(\beta=0.73, O R=2.08, Z=2.14, p=0.03,95 \% C I=0.06,1.40)$. When participants reported concurrent high levels of attachment to pets and high levels of social support, SGM status did not significantly predict intent to delay or avoid COVID-19 testing $(\beta=0.71, Z=1.57, p=0.12,95 \% C I=-0.18,1.61)$. Additionally, there was not a significant association between SGM status and the likelihood of delaying or avoiding COVID-19 testing when attachment to pets was at low or moderate levels. Figure $2 b$ reflects the plots of the conditional effects.

\subsubsection{Likelihood of Delaying or Avoiding COVID-19 Treatment}

When the likelihood of delaying or avoiding COVID-19 treatment was examined as the dependent variable, the overall additive multiple moderation model was a better fit for the data than the null model $(L L(14)=83.70, p<0.001)$ and accounted for some of the variance in the dependent variable (Cox and Snell $=0.06$, Nagelkerke $=0.12$ ). Similar to the previous models, SGM status was not significantly related to the likelihood of delaying or avoiding COVID-19 treatment ( $\beta=0.17, Z=0.66, p=0.51,95 \% C I=-0.35,0.70)$. Attachment to pets was positively related to the likelihood of delaying or avoiding COVID-19 treatment ( $\beta=0.33, Z=2.35, p=0.02,95 \% C I=0.05,0.60)$. In contrast, social support was negatively related to the likelihood to delay or avoid COVID-19 treatment $(\beta=-0.27, Z=-2.87$, $p=0.004,95 \% \mathrm{CI}=-0.46,-0.09$ ). Social support did not significantly moderate the relation between SGM status and intent to delay or avoid treatment for COVID-19 when attachment to pets was held constant $(\beta=-0.19, Z=-0.96, p=0.34,95 \% C I=-0.57,0.20)$. Similarly, attachment to pets did not significantly moderate this association when social support was held constant $(\beta=0.44, Z=1.44, p=0.15,95 \% \mathrm{CI}=-0.16,1.03)$. 


\section{Discussion}

This study aimed to investigate the relation between SGM status and the likelihood of delaying or avoiding testing and treatment for COVID-19, and whether these associations were moderated by attachment to pets and social support. We hypothesized that SGM participants, compared to non-SGM participants, would be more likely to endorse intent to delay or avoid COVID-19 testing and treatment. We also expected that the association between SGM status and the likelihood of delaying or avoiding COVID-19 testing and treatment would be strongest among those who report high levels of attachment to pets. Additionally, we hypothesized that SGM participants would be most likely to delay or avoid COVID-19 testing and treatment when they experienced high levels of attachment to pets and concurrently reported low levels of social support.

We did not find evidence to support our first hypothesis that SGM status would be significantly related to the likelihood to delay or avoid testing or treatment for COVID-19. This was surprising, given evidence that SGM individuals are more likely to avoid seeking out health care services due to experiences of discrimination by healthcare providers (Ayhan et al. 2020). It is possible that, given the deadly nature of COVID-19 (Centers for Disease Control and Prevention 2021a) and the increased risk faced by SGM communities (Gibb et al. 2020), the fear of contracting or dying from COVID-19 may exceed the concerns about discrimination that would otherwise impact healthcare decisions. It is also important to note that the vast majority of our SGM participants (95\%) reported having health insurance at the time the survey was conducted; this is in contrast to evidence from previous studies that suggest that SGM individuals report lower rates of health insurance compared to their cisgender and heterosexual counterparts (Whittington et al. 2020). This high endorsement of insurance may be due to the fact that our sample was under representative of people of color and those with a lower socioeconomic status, which are populations that are known to have lower rates of health insurance coverage compared to White individuals and/or those with high socioeconomic status (Chaudry et al. 2019; Sohn 2016; Stepanikova and Oates 2017). Although our analysis adjusted for the effects of healthcare insurance and other socioeconomic factors, replication in a sample with more diverse socioeconomic backgrounds is needed.

Our second hypothesis regarding the moderating role of attachment to pets on relations between SGM status and healthcare decision-making was partially supported. We found that attachment to pets significantly moderated the relationship between SGM status and the likelihood of delaying or avoiding testing for COVID-19. In particular, the results of the conditional effects suggested that SGM participants were more likely than non-SGM participants to indicate intent to delay or avoid testing only when they were highly attached to their pet. The significant moderation effect of attachment to pets in the additive multiple moderation analysis further illustrated the interplay between attachment to pets and social support, by suggesting that SGM participants were most likely to indicate they would delay or avoid testing for COVID-19 when attachment to pets was at high levels and social support was at moderate or low levels. This supports the hypothesis that SGM participants who experience high attachment to their pet, and are lacking a social support network (that could provide alternative care for their pet in their absence), may be forced into choosing between caring for their pet or risking their pet's safety by being hospitalized or quarantined away from them (per recommendations from the CDC and the American Veterinary Medical Association; Centers for Disease Control and Prevention 2021b; American Veterinary Medical Association 2021). These findings also coincide with evidence from prior studies that suggest that fear of being separated from one's pet could act as a barrier to one's willingness to seek medical care, especially among those with limited social support (Canady and Sansone 2019; Peacock et al. 2012). The results of this study build on existing research by highlighting how levels of attachment to pets and social support may add additional barriers that amplify the disproportionately lower rates of healthcare access among SGM individuals. 
Given the large number of individuals that have been hospitalized due to the COVID19 virus (Centers for Disease Control and Prevention 2021a), we anticipated that high levels of attachment to pets would also amplify the relation between SGM status and the likelihood of delaying or avoiding COVID-19 treatment. However, attachment to pets did not significantly moderate this association. This is surprising in light of prior evidence that pet ownership and strong bonds with pets are associated with a greater likelihood of avoiding medical treatment in the general population (Canady and Sansone 2019). Our results suggest that there may be different factors that play a role in deciding to seek testing versus treatment for COVID-19. One possible explanation is that if participants are already infected with COVID-19, they may be more motivated to seek treatment to avoid dying or becoming so ill that they could not continue to care for their pet. Indeed, there is evidence that owning and caring for pets may be a motivation to engage in healthier behaviors, such as increasing medication adherence and physical activity (Gupta et al. 2018; Hawkins et al. 2021; Hodgson et al. 2015; McDonald et al. 2021a). This may be a motivation that applies to all pet owners, which could explain why there is not a significant difference between SGM participants and participants who are cisgender and heterosexual. However, because there is a scarcity of studies investigating the role of pets in making healthcare decisions, especially healthcare decisions related to the COVID-19 pandemic, future longitudinal studies are needed to confirm this hypothesis.

\section{Limitations}

This study is not without limitations. Because this study collected data at the beginning of the COVID-19 pandemic, we were limited to measuring the likelihood of the intent to delay or avoid COVID-19 testing and treatment, and were not able to measure the actual behavior of participants. The purpose of this study was to investigate how COVID-19 related healthcare decisions may be influenced by relationships with pets and, thus, the phrasing of the two dependent variable questions was specific to measuring intent to delay or avoid COVID-19 testing and treatment because of concerns about pet welfare. However, we recognize that this phrasing could be considered leading and we understand that there may be many other reasons for delaying or avoiding COVID-19 related healthcare services. We were unable to measure and adjust for some factors that may have increased participants' risk of contracting COVID-19, and thus impacted healthcare decisions, such as existing health conditions or type of employment. Additionally, a majority of the sample identified as White, cisgender women who were economically advantaged. This is important to consider given evidence that levels of attachment to pets may vary by gender and race (Applebaum and Zsembik 2020; Herzog 2007; Khalid and Naqvi 2016). Therefore, it is possible that the results of this study may not be generalizable to all pet owners living in the U.S. Further, we were limited to combining sexual and gender minorities in our analyses due to the small proportion of gender minorities in our sample; best practices suggest analyzing sexual minorities and gender minorities separately due to differences in lived experiences (Schrager et al. 2019). Finally, the data were collected between the months of April and July of 2020, which represents the beginning months of the pandemic. It is possible that, as more information became publicly available in later months of the pandemic, participants' decisions regarding testing and treatment for COVID-19 may have changed.

\section{Conclusions}

Despite these limitations, this study has important implications for the health of pet-owning SGM individuals, and highlights potential directions for future research with this population. To our knowledge, this study is the first to investigate how relationships with pets may influence differences in COVID-related healthcare decisions between SGM and non-SGM individuals. This study has important theoretical implications, in that our findings provide support for the hypothesis that strong attachment to pets may contribute to decisions to delay or avoid healthcare services, particularly among populations that 
have limited access to social support, such as SGM individuals. Additionally, this study may have implications for researchers and practitioners employing a family systems theory perspective, as pets are often considered to be part of the family system (Hull and Ortyl 2019; Putney 2014) and these human-pet relationships may be particularly salient for SGM individuals who experience rejection from their families of origin (McDonald et al. 2021a). It is important for future research to explore the roles of pets in family systems from an SGM perspective and consider the mechanisms through which relationships with pets may factor into healthcare decisions and access. Because this study focused on the experiences of pet owners during the COVID-19 pandemic, we did not compare how healthcare decision-making may differ between SGM pet owners and SGM non-pet owners; this would be an important area for future researchers to explore. Additionally, future research in this area should be conducted with samples that are representative of diverse racial and gender identities and that can consider the impact of intersecting marginalized identities. Moreover, future studies would benefit from a longitudinal design that allows for causal inferences. Practitioners and community organizations working with SGM populations should implement strategies to address barriers to seeking healthcare services both during and beyond the COVID-19 pandemic. Based on these findings, it is critical that services targeting SGM individuals include alternative care plans for pets, such as boarding or fostering services.

Supplementary Materials: The following are available online at https: / www.mdpi.com/article / 10.3390/socsci10080301/s1, Table S1: Relations between Covariates and Outcomes in Moderation Models $(n=1453)$.

Author Contributions: Conceptualization, A.M., S.E.M. and J.W.A.; methodology, S.E.M. and J.W.A..; formal analysis, A.M.; resources, S.E.M. and J.W.A.; writing — original draft preparation, A.M., S.E.M., J.W.A. and S.K.K.; writing—review and editing, A.M., S.E.M., J.W.A. and S.K.K.; supervision, S.E.M.; project administration, J.W.A.; funding acquisition, J.W.A. and S.E.M. All authors have read and agreed to the published version of the manuscript.

Funding: Research reported in this publication was supported by the National Center for Advancing Translational Sciences of the National Institutes of Health under University of Florida and Florida State Unviersity Clinical and Translational Science Awards TL1TR001428 and UL1TR001427. The research reported in this publication was also supported by a National Institute of Health, Health Disparities Loan Repayment Program Award through the National Institute of Child Health and Human Development (1L60HD103238-01, PI: McDonald). The content is solely the responsibility of the authors and does not necessarily represent the official views of the National Institutes of Health.

Institutional Review Board Statement: The study was conducted according to the guidelines of the Declaration of Helsinki, and approved by the Institutional Review Board of University of Florida (protocol \#IRB202000819; 6 April 2020).

Informed Consent Statement: Informed consent was obtained from all subjects involved in the study.

Data Availability Statement: The data presented in this study are available on request from the second or fourth author. The data are not publicly available due to participant identifying information.

Acknowledgments: We thank Barbara A. Zsembik for her contributions to the research design and supervision during the development and data collection stages of this study. We would also like to acknowledge Camie Tomlinson, Jennifer Murphy, and Laura Booth for their assistance in the creation of and recruitment for this survey.

Conflicts of Interest: The authors declare no conflict of interest.

\section{References}

Adams, Britni L., Jennifer W. Applebaum, Michelle N. Eliasson, Shelby E. McDonald, and Barbara A. Zsembik. 2021. Child and Pet Care-Planning During COVID-19: Considerations for the Evolving Family Unit. Family Relations 70: 705-16. [CrossRef] [PubMed]

Ahmed, Faheem, Na'eem Ahmed, Christopher Pissarides, and Joseph Stiglitz. 2020. Why Inequality Could Spread COVID-19. The Lancet Public Health 5: e240. [CrossRef] 
American Veterinary Medical Association. 2021. COVID-19 FAQs for Pet Owners. Available online: https://www.avma.org/resourcestools / animal-health-and-welfare/covid-19/covid-19-faqs-pet-owners (accessed on 6 August 2021).

Applebaum, Jennifer W., and Barbara A. Zsembik. 2020. Pet Attachment in the Context of Family Conflict. Anthrozoös 33: 361-70. [CrossRef]

Applebaum, Jennifer W., Britni L. Adams, Michelle N. Eliasson, Barbara A. Zsembik, and Shelby E. McDonald. 2020a. How Pets Factor into Healthcare Decisions for COVID-19: A One Health Perspective. One Health 11: 100176. [CrossRef] [PubMed]

Applebaum, Jennifer W., Camie A. Tomlinson, Angela Matijczak, Shelby E. McDonald, and Barbara A. Zsembik. 2020b. The Concerns, Difficulties, and Stressors of Caring for Pets during COVID-19: Results from a Large Survey of U.S. Pet Owners. Animals 10: 1882. [CrossRef]

Ascione, Frank R., Claudia V. Weber, Teresa M. Thompson, John Heath, Mika Maruyama, and Kentaro Hayashi. 2007. Battered Pets and Domestic Violence: Animal Abuse Reported by Women Experiencing Intimate Violence and by Nonabused Women. Violence against Women 13: 354-73. [CrossRef] [PubMed]

Ayhan, Cemile Hurrem Balik, Hülya Bilgin, Ozgu Tekin Uluman, Ozge Sukut, Sevil Yilmaz, and Sevim Buzlu. 2020. A Systematic Review of the Discrimination Against Sexual and Gender Minority in Health Care Settings. International Journal of Health Services 50: 44-61. [CrossRef]

Beach, Lauren B., Tom A. Elasy, and Gilbert Gonzales. 2018. Prevalence of Self-Reported Diabetes by Sexual Orientation: Results from the 2014 Behavioral Risk Factor Surveillance System. LGBT Health 5: 121-30. [CrossRef]

Benfer, Emily A., David Vlahov, Marissa Y. Long, Evan Walker-Wells, J. L. Pottenger, Gregg Gonsalves, and Danya E. Keene. 2021. Eviction, Health Inequity, and the Spread of COVID-19: Housing Policy as a Primary Pandemic Mitigation Strategy. Journal of Urban Health 98: 1-12. [CrossRef]

Binnicker, Matthew J. 2020. Challenges and Controversies to Testing for COVID-19. Journal of Clinical Microbiology 58: e01695-20. [CrossRef]

Bowen, Jonathan, Elena García, Patricia Darder, Juan Argüelles, and Jaume Fatjó. 2020. The Effects of the Spanish COVID-19 Lockdown on People, Their Pets, and the Human-Animal Bond. Journal of Veterinary Behavior 40: 75-91. [CrossRef] [PubMed]

Caceres, Billy A., Abraham Brody, Rachel E. Luscombe, Jillian E. Primiano, Peter Marusca, and Deborah Chyun. 2017. A Systematic Review of Cardiovascular Disease in Sexual Minorities. American Journal of Public Health 107: e13-e21. [CrossRef] [PubMed]

Caceres, Billy A., Kasey B. Jackman, Donald Edmondson, and Walter O. Bockting. 2020. Assessing Gender Identity Differences in Cardiovascular Disease in US Adults: An Analysis of Data from the 2014-2017 BRFSS. Journal of Behavioral Medicine 43: 329-38. [CrossRef] [PubMed]

Canady, Brittany, and Ashley Sansone. 2019. Health Care Decisions and Delay of Treatment in Companion Animal Owners. Journal of Clinical Psychology in Medical Settings 26: 313-20. [CrossRef]

Carpenter, Christopher S., Samuel T. Eppink, and Gilbert Gonzales. 2020. Transgender Status, Gender Identity, and Socioeconomic Outcomes in the United States. ILR Review 73: 573-99. [CrossRef]

Centers for Disease Control and Prevention. 2021a. COVID Data Tracker. Available online: https:/ / covid.cdc.gov/covid-data-tracker (accessed on 25 June 2021).

Centers for Disease Control and Prevention. 2021b. What You Need to Know About COVID-19 and Pets. Available online: https: //www.cdc.gov/ coronavirus/2019-ncov/downloads/covid-19-pets-prevention.pdf (accessed on 6 August 2021).

Chaudry, Ajay, Adlan Jackson, and Sherry A Glied. 2019. Did the Affordable Care Act Reduce Racial and Ethnic Disparities in Health Insurance Coverage? New York: Commonwealth Fund 11: 1-10.

Cleary, Michelle, Denis Visentin, Deependra Kaji Thapa, Sancia West, Toby Raeburn, and Rachel Kornhaber. 2020. The Homeless and Their Animal Companions: An Integrative Review. Administration and Policy in Mental Health and Mental Health Services Research 47: 47-59. [CrossRef]

Couch, Kenneth A., Robert W. Fairlie, and Huanan Xu. 2020. Early Evidence of the Impacts of COVID-19 on Minority Unemployment. Journal of Public Economics 192: 104287. [CrossRef]

Czeisler, Mark É., Rashon I. Lane, Emiko Petrosky, Joshua F. Wiley, Aleta Christensen, Rashid Njai, Matthew D. Weaver, Rebecca Robbins, Elise R. Facer-Childs, Laura K. Barger, and et al. 2020. Mental Health, Substance Use, and Suicidal Ideation during the COVID-19 Pandemic-United States, June 24-30, 2020. Morbidity and Mortality Weekly Report 69: 1049-57. [CrossRef]

Dakin, Emily K., Kelly A. Williams, and Maureen A. MacNamara. 2020. Social Support and Social Networks among LGBT Older Adults in Rural Southern Appalachia. Journal of Gerontological Social Work 63: 768-89. [CrossRef]

Ettman, Catherine K., Salma M. Abdalla, Gregory H. Cohen, Laura Sampson, Patrick M. Vivier, and Sandro Galea. 2020. Prevalence of Depression Symptoms in US Adults Before and During the COVID-19 Pandemic. JAMA Network Open 3: e2019686. [CrossRef] [PubMed]

Fish, Jessica N., John Salerno, Natasha D. Williams, R. Gordon Rinderknecht, Kelsey J. Drotning, Liana Sayer, and Long Doan. 2021. Sexual Minority Disparities in Health and Well-Being as a Consequence of the COVID-19 Pandemic Differ by Sexual Identity. LGBT Health 8. [CrossRef]

Frost, David M., Ilan H. Meyer, and Sharon Schwartz. 2016. Social Support Networks among Diverse Sexual Minority Populations. The American Journal of Orthopsychiatry 86: 91-102. [CrossRef] 
Gibb, James K., L. Zachary DuBois, Sarah Williams, Luseadra McKerracher, Robert-Paul Juster, and Jessica Fields. 2020. Sexual and Gender Minority Health Vulnerabilities during the COVID -19 Health Crisis. American Journal of Human Biology 32: e23499. [CrossRef]

Gonzales, Gilbert, and Carrie Henning-Smith. 2017. Health Disparities by Sexual Orientation: Results and Implications from the Behavioral Risk Factor Surveillance System. Journal of Community Health 42: 1163-72. [CrossRef]

Gupta, Olga T., Deborah J. Wiebe, Elizabeth A. Pyatak, and Alan M. Beck. 2018. Improving Medication Adherence in the Pediatric Population Using Integrated Care of Companion Animals. Patient Education and Counseling 101: 1876-78. [CrossRef] [PubMed]

Hair, Joseph F., William C. Black, Barry J. Babin, and Rolph E. Anderson. 2010. Multivariate Data Analysis, 7th ed. Upper Saddle River: Pearson Education International.

Hawkins, Roxanne D., Emma L. Hawkins, and Liesbeth Tip. 2021. 'I Can't Give Up When I Have Them to Care for': People's Experiences of Pets and Their Mental Health. Anthrozoös 34: 543-62. [CrossRef]

Hayes, Andrew F. 2017. Introduction to Mediation, Moderation, and Conditional Process Analysis: A Regression-Based Approach, 2nd ed. New York: Guilford Publications.

Herzog, Harold A. 2007. Gender Differences in Human-Animal Interactions: A Review. Anthrozoös 20: 7-21. [CrossRef]

Hodgson, Kate, Luisa Barton, Marcia Darling, Viola Antao, Florence A. Kim, and Alan Monavvari. 2015. Pets' Impact on Your Patients' Health: Leveraging Benefits and Mitigating Risk. The Journal of the American Board of Family Medicine 28: 526-34. [CrossRef] [PubMed]

Holman, Alison E., Rebecca R. Thompson, Dana Rose Garfin, and Roxane Cohen Silver. 2020. The Unfolding COVID-19 Pandemic: A Probability-Based, Nationally Representative Study of Mental Health in the United States. Science Advances 6: eabd5390. [CrossRef]

Hull, Kathleen E., and Timothy A. Ortyl. 2019. Conventional and Cutting-Edge: Definitions of Family in LGBT Communities. Sexuality Research and Social Policy 16: 31-43. [CrossRef]

James, Sandy, Jody Herman, Susan Rankin, Mara Keisling, Lisa Mottet, and Ma'ayan Anafi. 2016. The Report of the 2015 U.S. Transgender Survey; Washington, DC: National Center for Transgender Equality. Available online: https://transequality.org/sites/default/ files/docs/usts/USTS-Full-Report-Dec17.pdf (accessed on 25 June 2021).

Johnson, Timothy P., Thomas F. Garrity, and Lorann Stallones. 1992. Psychometric Evaluation of the Lexington Attachment to Pets Scale (Laps). Anthrozoös 5: 160-75. [CrossRef]

Kamal, Kanika, Jason J. Li, Hyeouk Chris Hahm, and Cindy H. Liu. 2021. Psychiatric Impacts of the COVID-19 Global Pandemic on U.S. Sexual and Gender Minority Young Adults. Psychiatry Research 299: 113855. [CrossRef] [PubMed]

Kantamneni, Neeta. 2020. The Impact of the COVID-19 Pandemic on Marginalized Populations in the United States: A Research Agenda. Journal of Vocational Behavior 119: 103439. [CrossRef] [PubMed]

Khalid, Aliya, and Irum Naqvi. 2016. Relationship between Pet Attachment and Empathy among Young Adults. Journal of Behavioural Sciences 26: 66-81.

Krause, Kristen D. 2021. Implications of the COVID-19 Pandemic on LGBTQ Communities. Journal of Public Health Management and Practice 27: S69-S71. [CrossRef] [PubMed]

Leddy, Anna M., Sheri D. Weiser, Kartika Palar, and Hilary Seligman. 2020. A Conceptual Model for Understanding the Rapid COVID-19-Related Increase in Food Insecurity and Its Impact on Health and Healthcare. The American Journal of Clinical Nutrition 112: 1162-69. [CrossRef]

Lee Badgett, M. V., Soon Kyu Choi, and Bianca D. M. Wilson. 2019. LGBT Poverty in the United States. Available online: https: / / williamsinstitute.law.ucla.edu/publications/lgbt-poverty-us/ (accessed on 25 June 2021).

Little, Roderick J. A. 1988. A Test of Missing Completely at Random for Multivariate Data with Missing Values. Journal of the American Statistical Association 83: 1198-202. [CrossRef]

MacNamara, Maureen. 2019. LGBT Older Adults and Their Pets in Southern Appalachia: Results of Qualitative Research and Future Research Directions. Innovation in Aging 3: S201. [CrossRef]

Martino, Richard J., Kristen D. Krause, Marybec Griffin, Caleb LoSchiavo, Camilla Comer-Carruthers, Anita G. Karr, Allie F. Bullock, and Perry N. Halkitis. 2021. A Nationwide Survey of COVID-19 Testing in LGBTQ+ Populations in the United States. Public Health Reports 136: 493-507. [CrossRef] [PubMed]

May, Rachel. 2021. Pets Are Helping Us Cope during the Pandemic-But That May Be Stressing Them Out. National Geographic. Available online: https:/ / www.nationalgeographic.com/animals/article/pets-are-helping-us-cope-during-the-pandemic (accessed on 25 June 2021).

McDonald, Shelby E., Angela Matijczak, Nicole Nicotera, Jennifer W. Applebaum, Liza Kremer, Grace Natoli, Ryan O’Ryan, Laura J. Booth, Jennifer L. Murphy, Camie A. Tomlinson, and et al. 2021a. 'He Was like, My Ride or Die': Sexual and Gender Minority Emerging Adults' Perspectives on Living with Pets during the Transition to Adulthood. Emerging Adulthood. [CrossRef]

McDonald, Shelby E., Kelly E. O'Connor, Angela Matijczak, Camie A. Tomlinson, Jennifer W. Applebaum, Jennifer L. Murphy, and Barbara A. Zsembik. 2021b. Attachment to Pets Moderates Transitions in Latent Patterns of Mental Health Following the Onset of the COVID-19 Pandemic: Results of a Survey of U.S. Adults. Animals 11: 895. [CrossRef]

McGinty, Emma E., Rachel Presskreischer, Hahrie Han, and Colleen L. Barry. 2020. Psychological Distress and Loneliness Reported by US Adults in 2018 and April 2020. JAMA 324: 93-94. [CrossRef] [PubMed] 
Mirza, Shabab Ahmed, and Caitlin Rooney. 2018. Discrimination Prevents LGBTQ People from Accessing Health Care. Center for American Progress. Available online: https://www.americanprogress.org/issues/lgbtq-rights/news/2018/01/18/445130/ discrimination-prevents-lgbtq-people-accessing-health-care/ (accessed on 24 June 2021).

Moore, Scott Emory, Kelly L. Wierenga, Dana M. Prince, Braveheart Gillani, and Laura Janine Mintz. 2021. Disproportionate Impact of the COVID-19 Pandemic on Perceived Social Support, Mental Health and Somatic Symptoms in Sexual and Gender Minority Populations. Journal of Homosexuality 68: 577-91. [CrossRef]

Peacock, Jasmin, Anna Chur-Hansen, and Helen Winefield. 2012. Mental Health Implications of Human Attachment to Companion Animals. Journal of Clinical Psychology 68: 292-303. [CrossRef]

Phillips, Gregory, II, Jiayi Xu, Megan M. Ruprecht, Diogo Costa, Dylan Felt, Xinzi Wang, Erik Elías Glenn, and Lauren B. Beach. 2021. Associations with COVID-19 Symptoms, Prevention Interest, and Testing Among Sexual and Gender Minority Adults in a Diverse National Sample. LGBT Health 8. [CrossRef]

Putney, Jennifer M. 2014. Older Lesbian Adults' Psychological Well-Being: The Significance of Pets. Journal of Gay E Lesbian Social Services 26: 1-17. [CrossRef]

Ratschen, Elena, Emily Shoesmith, Lion Shahab, Karine Silva, Dimitra Kale, Paul Toner, Catherine Reeve, and Daniel S. Mills. 2020. Human-Animal Relationships and Interactions during the Covid-19 Lockdown Phase in the UK: Investigating Links with Mental Health and Loneliness. PLoS ONE 15: e0239397. [CrossRef]

Ratschen, Elena, Emily Shoesmith, and Roxanne Hawkins. 2021. Pets and the Pandemic: The Impact Our Animals Had on Our Mental Health and Wellbeing. The Conversation. Available online: http:/ / theconversation.com/pets-and-the-pandemic-the-impact-ouranimals-had-on-our-mental-health-and-wellbeing-153393 (accessed on 25 June 2021).

Rhoades, Harmony, Hailey Winetrobe, and Eric Rice. 2015. Pet Ownership among Homeless Youth: Associations with Mental Health, Service Utilization and Housing Status. Child Psychiatry \& Human Development 46: 237-44. [CrossRef]

Romero, Adam P., Shoshana K. Goldberg, and Luis A. Vasquez. 2020. LGBT People and Housing Affordability, Discrimination, and Homelessness. Williams Institute. Available online: https:/ / escholarship.org/uc/item/3cb5b8zj (accessed on 9 May 2021).

Schneebaum, Alyssa, and M. V. Lee Badgett. 2019. Poverty in US Lesbian and Gay Couple Households. Feminist Economics 25: 1-30. [CrossRef]

Schrager, Sheree M., Riley J. Steiner, Alida M. Bouris, Kathryn Macapagal, and C. Hendricks Brown. 2019. Methodological Considerations for Advancing Research on the Health and Wellbeing of Sexual and Gender Minority Youth. LGBT Health 6: 156-65. [CrossRef]

Sell, Randall L., and Elise I. Krims. 2021. Structural Transphobia, Homophobia, and Biphobia in Public Health Practice: The Example of COVID-19 Surveillance. American Journal of Public Health, e1-e7. [CrossRef] [PubMed]

Shadmi, Efrat, Yingyao Chen, Inês Dourado, Inbal Faran-Perach, John Furler, Peter Hangoma, Piya Hanvoravongchai, Claudia Obando, Varduhi Petrosyan, Krishna D. Rao, and et al. 2020. Health Equity and COVID-19: Global Perspectives. International Journal for Equity in Health 19: 104. [CrossRef] [PubMed]

Shanahan, Lilly, Annekatrin Steinhoff, Laura Bechtiger, Aja L. Murray, Amy Nivette, Urs Hepp, Denis Ribeaud, and Manuel Eisner. 2020. Emotional Distress in Young Adults during the COVID-19 Pandemic: Evidence of Risk and Resilience from a Longitudinal Cohort Study. Psychological Medicine, 1-10. [CrossRef]

Shoesmith, Emily, Lion Shahab, Dimitra Kale, Daniel S. Mills, Catherine Reeve, Paul Toner, Luciana Santos de Assis, and Elena Ratschen. 2021. The Influence of Human-Animal Interactions on Mental and Physical Health during the First COVID-19 Lockdown Phase in the U.K.: A Qualitative Exploration. International Journal of Environmental Research and Public Health 18: 976. [CrossRef]

Sohn, Heeju. 2016. Racial and Ethnic Disparities in Health Insurance Coverage: Dynamics of Gaining and Losing Coverage over the Life-Course. Population Research and Policy Review 36: 181-201. [CrossRef]

Stepanikova, Irena, and Gabriela R. Oates. 2017. Perceived Discrimination and Privilege in Health Care: The Role of Socioeconomic Status and Race. American Journal of Preventive Medicine 52: S86-S94. [CrossRef] [PubMed]

Stevenson, Rochelle, Amy Fitzgerald, and Betty Jo Barrett. 2018. Keeping Pets Safe in the Context of Intimate Partner Violence: Insights from Domestic Violence Shelter Staff in Canada. Affilia 33: 236-52. [CrossRef]

Veldhuis, Cindy B., Elizabeth D. Nesoff, Anna Laura W. McKowen, Dylan R. Rice, Hana Ghoneima, Angie R. Wootton, Elizabeth Lerner Papautsky, Danielle Arigo, Shoshona Goldberg, and Jocelyn C. Anderson. 2021. Addressing the Critical Need for Long-Term Mental Health Data during the COVID-19 Pandemic: Changes in Mental Health from April to September 2020. Preventive Medicine 146: 106465. [CrossRef]

Whittington, Charlie, Katalina Hadfield, and Carina Calderón. 2020. The Lives \& Livelihoods of Many in the LGBTQ Community Are at Risk Amidst COVID-19 Crisis. Human Rights Campaign Foundation. Available online: https:/ /assets2.hrc.org/files/assets / resources/COVID19-IssueBrief-032020-FINAL.pdf?_ga=2.30688191.1062621009.1585758332-1613644810.1567783041 (accessed on 9 May 2021).

Zimet, Gregory D., Nancy W. Dahlem, Sara G. Zimet, and Gordon K. Farley. 1988. The Multidimensional Scale of Perceived Social Support. Journal of Personality Assessment 52: 30-41. [CrossRef] 